\section{Modified Wrap-around Flap Incisional Method and Obser- vation of Donor Foot Effects}

\section{Sir,}

To repair degloving injury of thumb, wrap-around flap is an ideal method. By this method, not only the thumb reconstruction looks good, but also the number of toes does not change. At the same time, it is difficult to dissect the nail body by traditional operation, and it is difficult to care and treat the postoperative wound on the foot, which leads to obvious defects such as secondary injury of the graft body and donor foot, and eventually affects the postoperative walking speed and distance of the patients.

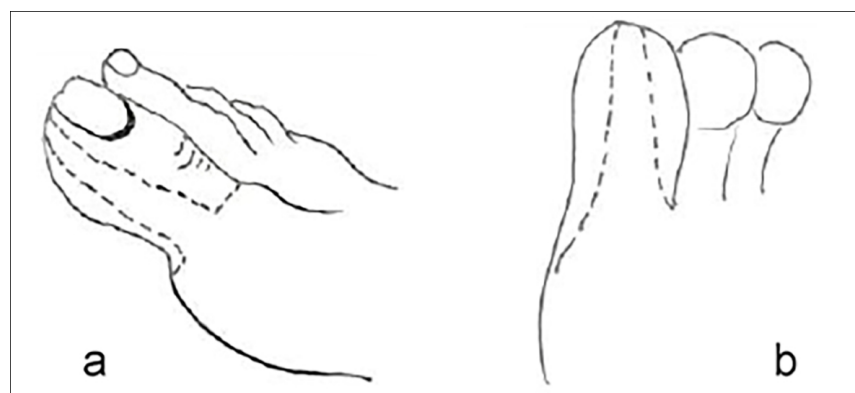

Figure 1: Diagrammatic sketch: (a) Sketch of conventional wrap-around flap foot retaining strip, (b) Sketch of modified wrap-around flap foot retaining strip.

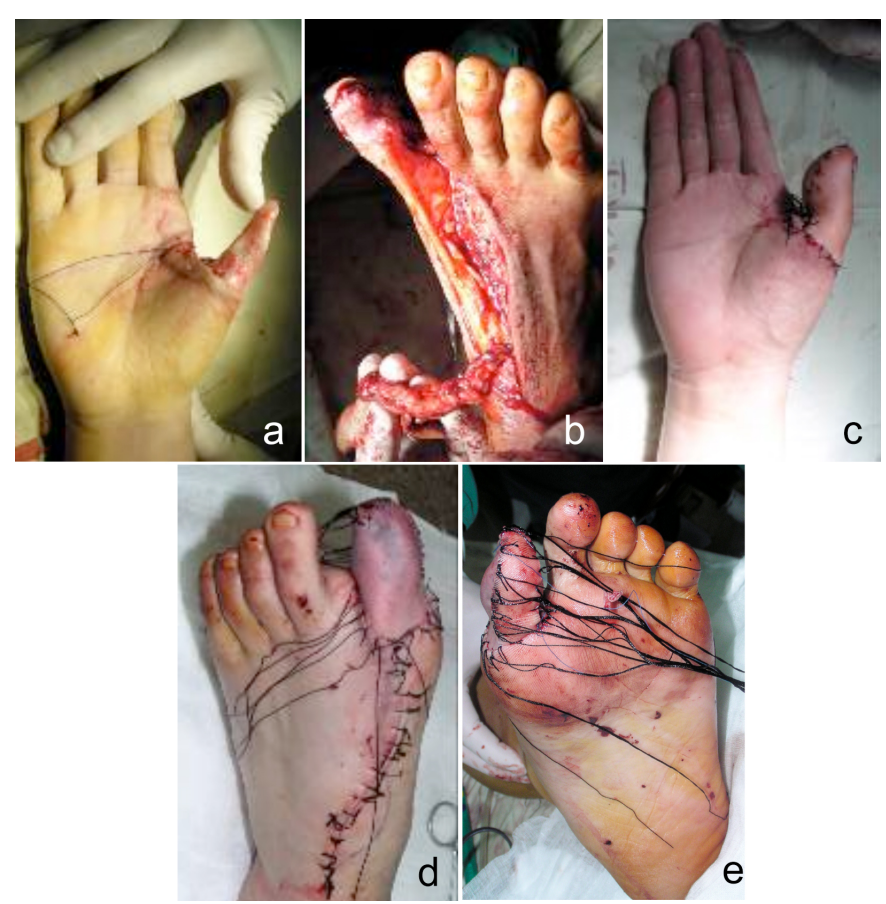

Figure 2: Operative technique: (a) Soft tissue defect of thumb, (b) wraparound flap dissociation, (c) Immediate hand appearance after wraparound flap transplantation, (d) Skin grafting on foot, (e) Weight-bearing area skin strip retained on sole of foot.

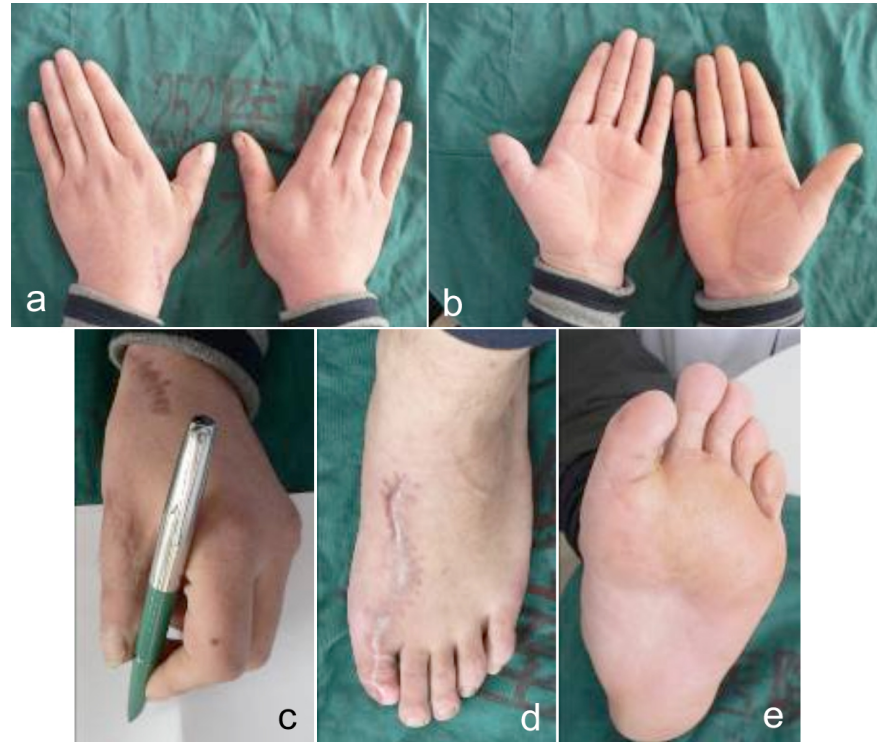

Figure 3: Postoperative view: (a), (b), (c) Hand shape and function 12 months afterflaptransplantation; (d), (e) The dorsal and volar conditions of the first toe.

In our hospital, from December 2009 to March 2017, 23 patients with thumb defects underwent wrap-around flap transplantation by modified incision - partial removal of the distal phalanx and preservation of the weight-bearing area of the sole. The follow-up of nail nutrition and donor function was carried not for 12 months to 2 years.

The innovative point of modified wrap-around flap incisional method is that it removes the nail body and the end of the first phalanges completely, and it keeps the middle thong of the palm of the toe (Figure 1). What is special about modified wraparound flap incisional method is that the nail flap is excised with the distal part of the first toe (about $1 / 2$ of the distal part of the toe) without separating the nail from the toe bone. The distal part of the toe bone, which is cut together, is transplanted into the defect area of the thumb. Preservation of fibular vascular nerve bundles in the flap, is more advantageous for the thumb to grasp and recover the sensory function when the peroneal nerve remains in the radial volar side of the thumb after the skin flap transplantation (Figure 2) ${ }^{1,2}$ Postoperatively the patient's nail body and foot supply remain in good condition (Figure 3 ).

Using the modified wrap-around flap incisional method for thumb reconstruction is safe and feasible, satisfactory, transplanted nail body can be obtained, and most of the complications of the donor feet can be significantly reduced. ${ }^{3}$ There are no Statistical significant differences in preoperative and postoperative walking speed and foot distance within 100 meters.

\section{CONFLICT OF INTEREST:}

None of the authors of this article have any commercial association that might pose or create a conflict of interest with the information presented in the submitted article.

\section{AUTHORS' CONTRIBUTION:}

$\mathrm{CH}$ : Substantial contributions to the conception and design of 
the work; the acquisition, analysis, or interpretation of data for the work; and drafting the work or revising it critically for important intellectual content; and final approval of the version to be published.

YL: Substantial contributions to the conception and design of the work.

SG: Interpretation of data for the work; and drafting the work or revising it critically for important intellectual content.

LZ: Drafting the work and revising it critically for important intellectual content.

\section{REFERENCES}

1. Adani R, Woo SH. Microsurgical thumb repair and reconstruction. J Hand Surg Eur Vol 2017; 42(8):771-8. doi: $10.1177 / 1753193417723310$.

2. Mario C, Martina C, Luigi V, Roberto A. Thumb reconstruction with thin proximal ulnar perforator free flap. J Hand Surg Am 2017; 42(2):e133-8. doi: 10.1016/j.jhsa.2016. 11.026 .
3. Cheema SA. Pedicled on-top plasty for thumb reconstruction: Utilization of proximal phalanx of an injured ring finger. J Coll Physicians Surg Pak 2015; 25(Suppl 1): S64-5.

Changqing $\mathrm{Hu}^{1}$, Yong $\mathrm{Lian}^{1}$, Shuqin Guo ${ }^{1}$ and Lei Zhu ${ }^{2}$ ${ }^{1}$ The Fifth Orthopaedics Department, The No. 1 Central Hospital of Baoding City, Hebei Province, Baoding, China ${ }^{2}$ Department of Anesthesiology, The No.1 Central Hospital of Baoding City, Hebei Province, Baoding, China

Correspondence to: Dr. Changqing Hu, The Fifth Orthopaedics Department, The No.1 Central Hospital of Boading City, Baoding, Hebei, China

E-mail: changqing780107@163.com

Received: July 09, 2019; Revised: January 01, 2020; Accepted: January 01, 2020

DOI: https://doi.org/10.29271/jcpsp.2020.10.1109 